\title{
Service Delivery Factors That Influence Utilization of HIV Integrated Primary Health Care Programme in Embu Referral Hospital, Kenya
}

\author{
Caroline N. Githae', Micah Matiang'í2, Moses Muraya ${ }^{3}$ \\ ${ }^{1}$ Department of Nursing, Chuka University, Chuka, Kenya \\ ${ }^{2}$ Department of Maternal, Child Health, Amref International University, Nairobi, Kenya \\ ${ }^{3}$ Department of Molecular Genetics, Chuka University, Chuka, Kenya \\ Email: nyaguthiek@gmail.com, Micah.matiangi@amref.org, moses.muraya@gmail.com
}

How to cite this paper: Githae, C.N., Matiang'i, M. and Muraya, M. (2019) Service Delivery Factors That Influence Utilization of HIV Integrated Primary Health Care Programme in Embu Referral Hospital, Kenya. Open Journal of Clinical Diagnostics, 9, 71-89.

https://doi.org/10.4236/ojcd.2019.93006

Received: July 31, 2019

Accepted: September 22, 2019

Published: September 25, 2019

Copyright () 2019 by author(s) and Scientific Research Publishing Inc. This work is licensed under the Creative Commons Attribution International License (CC BY 4.0).

http://creativecommons.org/licenses/by/4.0/

\section{Open Access}

\begin{abstract}
Globally, there are approximately 36.7 million people living with HIV. Integration of HIV treatment with primary care services improves effectiveness, efficiency and equity in service delivery. The study sought to establish service delivery factors that influenced utilization of integrated HIV and primary health care services in Embu Teaching and Referral hospital. A descriptive cross-sectional survey design was used to collect data at a specific period and point of time from a sample of 302 seropositive clients who were selected using simple random method. Data collection tool was structured and semi-structured questionnaire. The tool was reliable at Cronbach's alpha of 0.817 . SPSS version 23 was used to analyze the data. A binary logistic regression model was used to predict the relationship between service delivery and utilization of integrated services. Results: Majority of the respondents (59.6\%) were aged over 35 years with majority being female (58.9\%) and the married were $57.6 \%$ of the total sample. On service delivery factors, majority (94.7\%) felt that their health status had improved. Action taken when clients developed side effects, $78.8 \%$ reported that the drugs were changed. Action taken following drug side effects significantly affected utilization, $\chi^{2}=1.305, p$ $=0.001, \mathrm{df}=1$. The findings showed that waiting time significantly influenced utilization, $\chi^{2}=9.284 \mathrm{df}=1, p=0.002$. Source of information on self care also significantly influenced utilization, $\chi^{2}=10.689, \mathrm{df}=1, p=0.001$. Kind of treatment at the facility also significantly influenced utilization, $\chi^{2}=$ 5.713, $p=0.048$. Conclusion: significant factors that influenced utilization of integrated services were source of health care information, secondly waiting
\end{abstract}


time was another factor which influenced utilization. Majority of the respondents were satisfied with duration of time they take before they were served; they reported to take utmost 1 hour to be attended to and action taken by health care provider following side effects was another factor that influenced the utilization.

\section{Keywords}

Service Related Factors, Integrated Services, Embu Teaching and Referral Hospital, HIV Patients, Primary Health Care Services

\section{Introduction}

Globally, there are approximately 36.7 million people living with HIV in the year 2017-2018, with an estimated 3.8 million individuals newly infected with HIV and about 5000 new infections per day [1]. Among these people, 2.1 million are children and teenagers below 15 years of age, and most of them from sub Saharan Africa. The vast majority of people living with HIV are in low- and middle-income countries. In 2017, there were 19.6 million people living with HIV (53\%) in eastern and southern Africa, 6.1 million (16\%) in western and central Africa, 5.2 million (14\%) in Asia and the Pacific, and 2.2 million (6\%) in Western and Central Europe and North America. Despite implementing some of the preventive measures many people living with HIV or at risk for HIV still do not have access to proper care and treatment [1].

Efforts have been made by the global community to prevent HIV and treat related illnesses. However too many people with or at risk of contracting HIV have no access to care, treatment and prevention [1]. Nevertheless, global goal achievement of zero new HIV infections, zero AIDS-related deaths and zero discrimination has been achieved in most developed countries. In Asia and Pacific region remarkable progress has been made as indicated by $26 \%$ decline in new HIV infections from 2001-2012 and a 46\% increase in access to Antiretroviral Therapy (ART) from 2009 to 2012 [2]. Majority of developing countries need more time to achieve the zero new HIV infections goal. They need to be more innovative in treatment, prevention and putting up more programs to be able to achieve the overall goal. Some of the pillars have been put in place to achieve this goal and one of the pillars is to adapt delivery systems. This entails decentralisation and integration of HIV care and treatment with other HIV and non-HIV services such as drug dependency services, maternal, new-born and child health or Tuberculosis services. The primary aim of this pillar is to increase community engagement for HIV testing and counselling, care retention and early initiation of ART [2].

In Sub-Saharan Africa, integration of HIV and family planning services has been shown to have several benefits [3]. Services rendered are affordable to clients, reduction of stigma and discrimination. Other studies conducted in South 
Africa on perception of integration of HIV and sexual reproductive health care, suggested a preference for integrated care among female clients, particularly because of stigma reduction and higher access to contraceptives [4]. Some of the perception of clinicians and clients on the integration of primary health care and HIV services showed that about $80 \%$ of the respondents were satisfied with integration because the organization of services and confidentiality prevented stigma and discrimination. Majority of participants in the fully and partially integrated facilities reported that clinicians treated them with respect, privacy and confidentiality. Other participants referred staffs as rude and unfriendly, increased waiting time before one is attended to, interruption of consultation which was seen as infringement of privacy. A similar study showed that clients felt that there were delays related to lack of punctuality to report on duty after lunch and tea break, poor staff communication regarding delays in patients consultations like when they break for lunch the staffs do not communicate to the clients [5].

Majority of the respondents in a study conducted in Ethiopia reported positive feelings towards the disease and therefore can disclose their status to their families comfortably and $50 \%$ of the respondents mentioned that TB carries the same stigma as HIV, this kind of stigma is reduced when integration of services is embraced [6]. Integration of HIV services and TB treatment demonstrated relative success of integrated and co-located TB/HIV services in Swaziland, and revealed timely ART uptake for HIV-positive TB patients in resource-limited, but integrated settings [7].

A research carried out on patients' perception on HIV treatment integration with other services reported that most clients were satisfied with the integration of services [8]. However, the clients reported that the staffs' attitude, number of staffs in health facilities and health care provider, patient communication were significantly affecting patients' satisfaction levels. In Cameroon integration has led to increased utilization of HIV services, therefore when integration is implemented well and staffs' attitude and communication improved; patient level of satisfaction was predicted to improve significantly [8].

In western Kenya, men who were received integrated services for HIV care and family planning reported improved service delivery, personal health and increased chances of prevention of mother to child HIV transmission. This was associated with use of ART and contraceptives, these men reported to have been counselled on adherence to ART and use of condom and they were supplied with the condoms. In the same report it was indicated that most men preferred the integrated clinic to be at their initial HIV care clinic and not in the MCH/FP clinic, this was due to trust developed between them and their care providers [9]. Patients receiving services from integrated clinics had improved satisfaction and perceived quality care compared to those in separate clinics. However, the cost and availability of the resources was cited as a barrier to the implementation of the integrated services.

A recent review identified various discriminatory behaviours and negative attitudes towards HIV patients. Some of the behaviours were denial of care, and 
testing or status disclosure without consent, verbal abuse, additional fee and overuse of gloves especially health care providers on HIV patients. It has been speculated that stand alone HIV services may be stigmatizing, as clients are labelled as they walk through the door resulting in an involuntary disclosure of status. Other structural influences include avoidance or isolation of HIV clients and labelling of buildings and rooms [9]. Integration is also likely to reorganize health care delivery which may disrupt service provision and cause dissatisfaction among patients. Further integration of specialized services into primary care services may not always result in better patient and service level outcomes for example integration of HIV services with sexual and reproductive health services may be hindered by increased patient burden, inadequate staffing and resistance from existing health care workers. Integrating services for STI into routine health services may result in lower utilization and reduced patient satisfaction [10].

In Embu County, HIV prevalence is at 3.3\% according to Kenya HIV Estimates 2015. The County contributed $0.7 \%$ of the people living with HIV in Kenya, with women having a higher prevalence $(4.5 \%)$ than that of men $(2.0 \%)$. In a report released by Kenya Demographic Health Survey in 2014, it is evident that $36 \%$ of men and $16 \%$ of women in Embu County never sought HIV testing services; therefore the county needs more innovative strategies to improve on HIV testing and counselling, reduce HIV related stigma and promote client satisfaction towards HIV services, to bridge the unmet gaps [11]. The study findings will assist national government to formulate policies which will improve services provided under integrated arrangement. The findings will also empower county government to support the facility under study and other facilities in the region to integrate more services in order to increase utilization.

\section{Methodology}

A cross-sectional descriptive survey design was used to generate both quantitative and qualitative data. This design was appropriate since the study was carried out at a specific point in time without any manipulation of the variables. The descriptive survey design was appropriate since the study entailed description of the phenomena or the subjects under study as accurately as possible without manipulation of variables. The study population in this study were seropositive HIV clients. A target population of 1650 clients was applied as per the comprehensive care clinic register; approximately 55 clients per day receive HIV services, a sample of 302 respondents was used in the study. The study included HIV clients above 18 years of age and those enrolled for treatment at the clinic. It excluded those who did not consent to participate in the study, clients below 18 years of age and those enrolled on the day of data collection. They were appropriate for this study because they are informed about integration and they are the main beneficiaries of these services. Reliability of the tool was tested and the Cronbach's alpha was calculated and was found to be at $(p=0.817)$ which showed a high degree of reliability of the variables. 
Quantitative data was analyzed using SPSS version 23. Descriptive statistics i.e. frequencies and percentages were used first to show the service delivery related factors. Bivariate analysis i.e. chi-square was then performed to show the relationship between specific service delivery factors and dependent variables i.e. utilization indicators. Finally, regression analysis was done to determine the set of service delivery related factors that significantly influenced the utilization level of integrated HIV and primary health care services. 5\% level of significance was applied on all analyses.

All the respondents signed a written consent form before participating in the study. The ethical principles of beneficence, non-maleficence and autonomy observed and the respondents' information was kept confidential.

\section{Results and Discussion}

\subsection{Demographic Characteristics}

The study showed that more than half of respondents (50.6\%) were 35 years and above, followed by those between 32 - 35 at $21.2 \%$. The age group of $27-31$ was the least with $1.7 \%$ those between 18 - 22 years were $8.9 \%$ (Table 1 ). The majority of the respondents i.e. $58.9 \%$ were females while $41.1 \%$ were males. Most of the respondents were married (57.6\%), single were $36.8 \%$ and divorced were the least with 5.6\%. Protestants were 51\% while Muslims were the least $(1.3 \%)$. With respect to level of education, most of the respondents attended secondary school (38.1\%), followed by primary school (36.8\%). Most of the respondents were self employed (49.7\%) and the least were unemployed (16.2\%). More than half of the respondents reported that distance to the facility was $4-5 \mathrm{~km}$ (58.9\%).

According to the findings of this study the majority of the respondents were aged 35 years and above (59.6\%). It was noted that during the interview that this age group had utilized the services for many years. Majority of the respondents were married and most of them were females. The findings on gender agree with KDHS study, which showed that in Embu County, women have a higher HIV prevalence than that of men [11]. These findings concurred with a study that was conducted in Vietnam on level of satisfaction which indicated satisfaction as a factor on utilization of health services [12]. [13] reported that age, marital status and female gender were associated with higher rates of satisfaction which significantly affects their level of utilization.

All the respondents were on ART at the time of data collection. Majority i.e. $75.2 \%$ (227) had been on ART for more than 24 months, $21.5 \%$ (65) had been on ART for 12 - 24 months while 3.3\% (10) had been on ART for up to 12 months.

Majority i.e. 98.7\% (298) had received the combined HIV care and other services under one roof, while $1.3 \%$ (4) had not. Concerning duration of medical care in the clinic, $0.7 \%$ (2) had received care for less than 1 year, $27.8 \%(84)$ had received care for 1 - 2 years, and $26.8 \%$ (81) had received care for 3-5 years while $44.7 \%$ (135) had received care for more than 5 years (Table 2). 
Table 1. Non-illness related demographic characteristics.

\begin{tabular}{|c|c|c|}
\hline Characteristic & Frequency (n) & Percent (\%) \\
\hline \multicolumn{3}{|l|}{ Age in years } \\
\hline $18-22$ & 27 & 8.9 \\
\hline $23-26$ & 26 & 8.6 \\
\hline $27-31$ & 5 & 1.7 \\
\hline $32-35$ & 64 & 21.2 \\
\hline Over 35 & 180 & 59.6 \\
\hline Total & 302 & 100 \\
\hline \multicolumn{3}{|l|}{ Gender } \\
\hline Male & 124 & 41.1 \\
\hline Female & 178 & 58.9 \\
\hline Total & 302 & 100 \\
\hline \multicolumn{3}{|l|}{ Marital status } \\
\hline Married & 174 & 57.6 \\
\hline Single & 111 & 36.8 \\
\hline Divorced & 17 & 5.6 \\
\hline Total & 302 & 100 \\
\hline \multicolumn{3}{|l|}{ Religion } \\
\hline Catholic & 130 & 43 \\
\hline Protestant & 154 & 51 \\
\hline Muslim & 14 & 4.6 \\
\hline Others & 4 & 1.3 \\
\hline Total & 302 & 100 \\
\hline \multicolumn{3}{|l|}{ Level of education } \\
\hline Primary & 111 & 36.8 \\
\hline Secondary & 115 & 38.1 \\
\hline Tertiary & 66 & 21.9 \\
\hline Others & 10 & 3.3 \\
\hline Total & 302 & 100 \\
\hline \multicolumn{3}{|l|}{ Employment status } \\
\hline Employed & 103 & 34.1 \\
\hline Unemployed & 49 & 16.2 \\
\hline Self-employed & 150 & 49.7 \\
\hline Total & 302 & 100 \\
\hline \multicolumn{3}{|c|}{ Distance from home to facility } \\
\hline Below $1 \mathrm{~km}$ & 27 & 8.9 \\
\hline $2-3 \mathrm{~km}$ & 91 & 30.1 \\
\hline $4-5 \mathrm{~km}$ & 178 & 58.9 \\
\hline Above $6 \mathrm{~km}$ & 6 & 2 \\
\hline Total & 302 & 100 \\
\hline
\end{tabular}

Most of the respondents in Figure 1 i.e. 35.1\% (106) were seeking ART services and health education, while the services least sought after were immuniza- 
tion and curative services with $2 \%(6)$ and $1.3 \%(4)$ respectively.

\subsection{HIV Patients' Utilization of Integrated HIV and Primary Health Care Services}

Utilization level was determined by the number of items that respondents utilized as recommended. Out of five items, those who utilized at least 4 out five were considered as utilizing integrated HIV and primary health care services while those who utilized below 4 were considered as not utilizing the services. The findings of this study showed that $99.3 \%$ of the respondents visited the health facility immediately whenever they experienced an illness related to HIV infection, while $0.7 \%$ tried other measures at home (Table 3 ). The majority i.e. $66.9 \%$ had ever missed appointment given in the course of care while $33.1 \%$ had never missed any appointment. Most respondents i.e. $77.8 \%$ had never missed to take any drugs or treatment options given in the facility of care while $22.2 \%$ had missed some treatment. Concerning use of alternative medicine outside conventional prescribed medical care, all the respondents were found to avoid such treatments. Likewise, all the respondents consulted the facility care provider whenever they had bothering questions about the care they were receiving (Table 3).

The findings on drug adherence agree with [14] findings which showed that most patients were satisfied with the services offered by the care providers, they were informed on how the drugs work and through this the patients could adhere to treatment. The findings of this study demonstrated that the level of utilization of integrated HIV and primary care service was quite impressive because majority of respondent had never missed any appointments. Moreover, most of them were adhering to the treatment and they were consulting health workers on areas not clear to them. These findings were in agreement with those of [4].

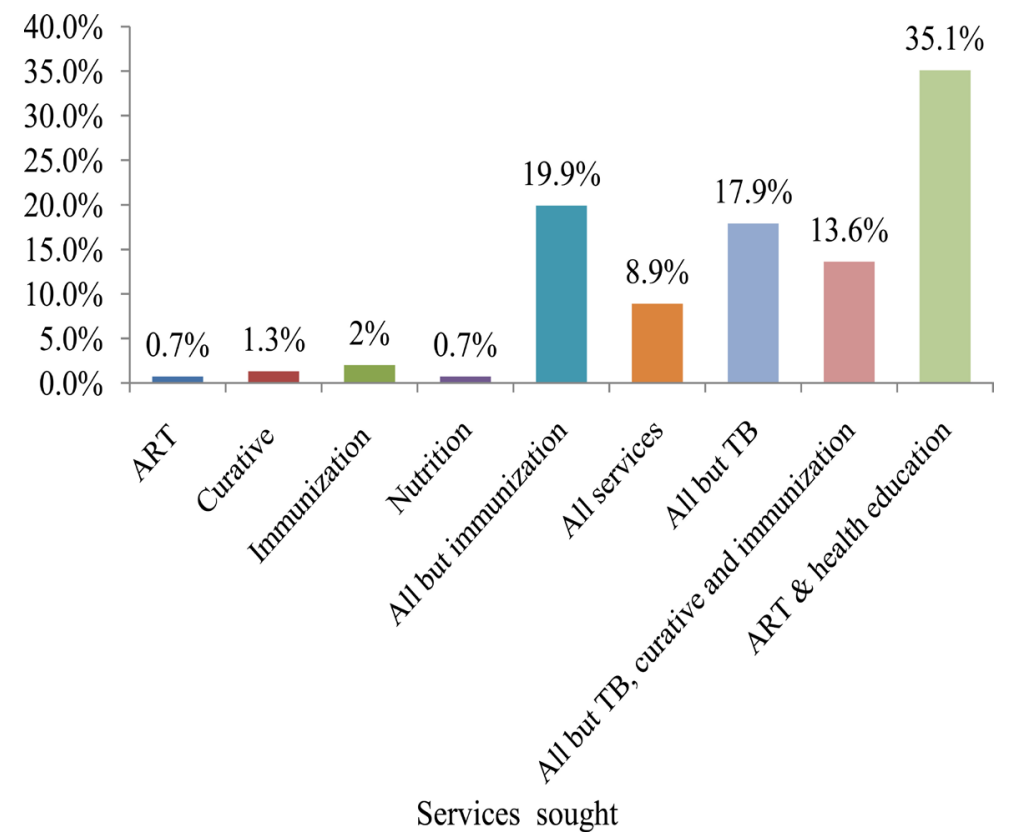

Figure 1. Services sought at the clinic. 
Table 2. Illness related demographic characteristics.

\begin{tabular}{ccc}
\hline Characteristic & Frequency (n) & Percentage (\%) \\
\hline If currently on ART & 302 & 100 \\
Yes & 0 & 0 \\
No & 302 & 100 \\
Total & & \\
Duration on ART & 10 & 3.3 \\
Up to 12 months & 65 & 21.5 \\
12 - 24 months & 227 & 75.2 \\
Over 24 months & 302 & 100 \\
Total & & \\
\hline Combination of HIV \& other services under one roof & 298 & 98.7 \\
Yes & 4 & 1.3 \\
No & 302 & 100 \\
Total & & \\
Duration of medical care & 2 & 0.7 \\
Less than 1 year & 84 & 27.8 \\
1 - 2 years & 81 & 26.8 \\
3 - 5 years & 135 & 44.7 \\
More than 5 years & 302 & 100 \\
Total & &
\end{tabular}

Table 3. Overall utilizations of integrated HIV and primary care services.

\begin{tabular}{ccc}
\hline Service indicator & Utilization (\%) & Non-utilization (\%) \\
\hline Action taken after HIV related illness & 99.3 & 0.7 \\
Appointments given in the clinic & 66.9 & 33.1 \\
Taking prescribed drugs & 77.8 & 22.2 \\
Avoidance of alternative medicine & 100 & 0 \\
Consultations on areas not clear & 100 & 0 \\
\hline
\end{tabular}

The integration of HIV care and TB is perceived to increase adherence to medication and early initiation of treatment because of frequent follow ups and reminders done by health workers. There is a positive association between integration of the services and lower CD4 counts, which was accounted for by adherence to medication and early initiation of ART and TB treatment. In this study more than a half of the respondents i.e. $86.8 \%$ utilized integrated HIV and primary health care services while $12.9 \%$ did not (Figure 2).

Figure 2 shows that majority of the respondents i.e. 86.8\% (262) utilized integrated HIV and primary health care services while $12.9 \%$ (39) did not.

\subsection{Influence of Service Delivery Characteristics on Utilization of Integrated HIV and Primary Health Care Services \\ Perceived Improvement of Health Status and Utilization of Integrated HIV and Primary Health Care Services}

Most respondents (94.7\%) felt that their health statuses had improved while 
5.3\% felt the health statuses had not improved. Perceived improvement in health status did not influence utilization of integrated HIV and primary health care services $\left(\chi^{2}=0.003, \mathrm{df}=1 ; p=0.959\right.$; Table 4$)$. The findings implied that respondent's perceived improvement in health status did not influence utilization of integrated HIV and primary health care services [15]. The findings differs with those of [16] reported that dissatisfaction of the patients towards integrated services is related to increased workload for the staffs which led to reduction in quality of care, his findings reflected failure of the staffs to rule out opportunistic infections and some defaulting on their treatment schedule leading to deterioration of their health status. [17] found that in a total of 185 (93.7\%) of the respondents reported that their health status had improved since starting antiretroviral treatment. Most of the respondents during the interview reported improvement in health status since they started using the facility but others said that they did not see any change in their health status but they still utilize the facility because of convenience in relation to time and distance.

\section{Action Taken Following Drug Side Effects and Utilization of Integrated} HIV and Primary Health Care Services

This study showed that when patients developed drug side effects, $5.3 \%$ of them were referred to another facility, $5.6 \%$ no action was taken, $78.8 \%$ drugs were changed, $8.9 \%$ were treated for side effects, $1.3 \%$ stopped taking medication (Table 5).

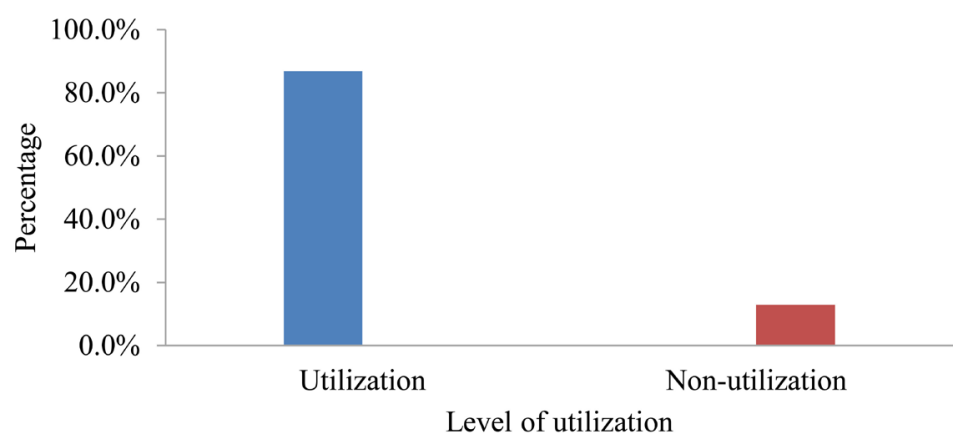

Figure 2. Utilization level of HIV integrated primary health care services.

Table 4. Association between perceived improvement in health and utilization of integrated HIV and primary health care services.

\begin{tabular}{cccccc}
\hline & Value & df & $\begin{array}{c}\text { Asymp. sig. } \\
\text { (2-sided) }\end{array}$ & $\begin{array}{c}\text { Exact sig. } \\
\text { (2-sided) }\end{array}$ & $\begin{array}{c}\text { Exact sig. } \\
\text { (1-sided) }\end{array}$ \\
\hline Pearson chi-square & $0.003^{\mathrm{a}}$ & 1 & 0.960 & & \\
Continuity correction ${ }^{\mathrm{b}}$ & 0.000 & 1 & 1.000 & & \\
$\quad$ Likelihood ratio & 0.003 & 1 & 0.959 & & 0.658 \\
$\begin{array}{c}\text { Fisher's exact test } \\
\text { Linear-by-linear association }\end{array}$ & 0.003 & 1 & 0.960 & & \\
N of valid cases & 302 & & & &
\end{tabular}

a. 1 cells $(25.0 \%)$ have expected count less than 5 . The minimum expected count is 2.07 . b. Computed only for a $2 \times 2$ table. 
The correct action taken was supposed to be any action except referral and no action at all. This would indicate that the service was of good quality. The actions taken were cross-tabulated against utilization and chi squared tests of association were run. Action taken followed development of drugs side effects significantly influenced utilization of integrated HIV and primary health care services $\left(\chi^{2}=1.305, \mathrm{df}=1, p=0.001\right.$; Table 5$)$.

Those who received the correct course of action were 4.5 times likely to utilize the integrated HIV and primary health care services (Table 6). The findings above show that the clients adhere to treatment. Most respondent said that drugs were changed $(78.8 \%)$ and $8.9 \%$ said that were treated for side effects. The respondents

Table 5. Action taken after drug side effects.

\begin{tabular}{ccc}
\hline Action & Frequency (n) & Percent (\%) \\
\hline Was referred to another facility & 16 & 5.3 \\
Nothing was done & 17 & 5.6 \\
Drugs were changed & 238 & 78.8 \\
Was treated for side effects & 27 & 8.9 \\
Stopped taking medication & 4 & 1.3 \\
Total & 302 & 100.0 \\
\hline
\end{tabular}

Table 6. Association between action taken after side effects and utilization of integrated HIV and primary health care services.

\begin{tabular}{cccccc}
\hline & Value & df & $\begin{array}{c}\text { Asymp. sig. } \\
(2 \text {-sided })\end{array}$ & $\begin{array}{c}\text { Exact sig. } \\
(2 \text {-sided })\end{array}$ & $\begin{array}{c}\text { Exact sig. } \\
(1 \text {-sided })\end{array}$ \\
\hline $\begin{array}{ccccc}\text { Pearson chi-square } \\
\text { Continuity correction }{ }^{\mathrm{b}}\end{array}$ & $14.659^{\mathrm{a}}$ & 1 & 0.000 & & \\
$\quad 12.602$ & 1 & 0.000 & & \\
$\quad$ Likelihood ratio & 11.305 & 1 & 0.001 & & 0.001 \\
Fisher's exact test & & & & & \\
Linear-by-linear association & 14.610 & 1 & 0.000 & & \\
N of valid cases & 302 & & & & \\
\hline
\end{tabular}

a. 1 cells $(25.0 \%)$ have expected count less than 5 . The minimum expected count is 4.13 . b. Computed only for a $2 \times 2$ table.

Risk Estimate

\begin{tabular}{lccc}
\hline & Value & 95\% Confidence interval \\
\cline { 3 - 4 } & & Lower & Upper \\
\hline $\begin{array}{l}\text { Odds ratio for utilization versus non-utilization } \\
\text { (utilization/non-utilization) }\end{array}$ & 4.527 & 1.978 & 10.359 \\
$\begin{array}{l}\text { For cohort what happened when you developed } \\
\text { ART drugs related side effects = quality }\end{array}$ & 1.282 & 1.049 & 1.565 \\
$\begin{array}{l}\text { For cohort what happened when you developed } \\
\text { ART drugs related side effects = not quality }\end{array}$ & 0.283 & 0.148 & 0.541 \\
N of valid cases & & & \\
\hline
\end{tabular}


said that they did not have fears and concerns related to the side effects because of the competent interventions by the health workers. This admits to a study by [14], whose findings stated that care providers offered information on drugs effects and contraindications. They also encouraged the patients to air out any concerns related to drugs.

Waiting Time before Service Delivery and Utilization of Integrated HIV and Primary Health Care Services

With respect to waiting time, this study revealed that $7.3 \%$ of the patient waited for 30 minutes to be served, 55.3\% waited for 30 minutes to 60 minutes, $19.9 \%$ waited for 60 - 120 minutes and $17.5 \%$ waited for more than 120 minutes (Figure 3).

Waiting time was collapsed into two i.e. one hour and below and more than one hour ( 2 by 2 table to facilitate cross tabulation). Waiting times significantly influenced utilization of integrated HIV and primary health care services $\left(\chi^{2}=\right.$ 9.284, $\mathrm{df}=1, p=0.002$ ) whereby those who waited for 1 hour or less were unlikely to utilize the integrated HIV and primary health care services as shown in Table 7. The findings implied that duration of time taken to be served influence utilization of integrated HIV and primary health care services, after cross tabulation, those who reported to have taken short time to be served that is 1 hour and less were less likely to utilize integrated services. The findings are in agreement with a study conducted in South Africa, which showed that duration of time the patient took before receiving the services was associated with increased utilization of services long waiting time at the clinic as a result of integration had a negative impact on utilization of integrated services [16].

Appointment Reminders and Utilization of Integrated HIV and Primary Health Care Services

All the respondents were receiving reminders for the next visit after leaving the health facility through various means: $14.9 \%$ were reminded through word of mouth, $48.3 \%$ through appointment cards, 30.8\% through mobile phone, $4.6 \%$ through community health worker and $1.3 \%$ through appointment card and text messages (Figure 4).

Majority of the respondents said that they are reminded on next appointment through mobile phones (30.8\%). These findings were replicated in a study on

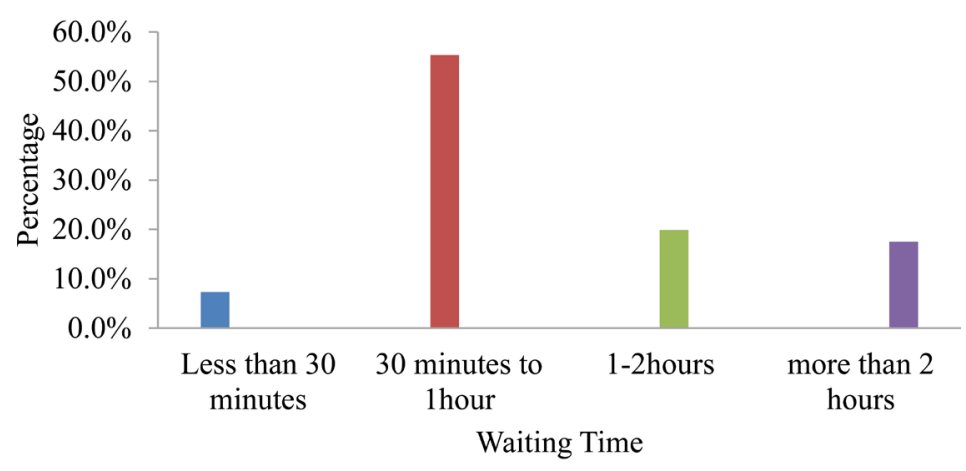

Figure 3. Respondents' waiting time before service delivery. 
Table 7. Association between waiting times and utilization of integrated HIV and primary health care services.

\begin{tabular}{|c|c|c|c|c|c|}
\hline & Value & $\mathrm{df}$ & $\begin{array}{l}\text { Asymp. sig. } \\
\text { (2-sided) }\end{array}$ & $\begin{array}{l}\text { Exact sig. } \\
\text { (2-sided) }\end{array}$ & $\begin{array}{l}\text { Exact sig. } \\
\text { (1-sided) }\end{array}$ \\
\hline Pearson chi-square & $9.284^{\mathrm{a}}$ & 1 & 0.002 & & \\
\hline Continuity correction ${ }^{\mathrm{b}}$ & 8.235 & 1 & 0.004 & & \\
\hline Likelihood ratio & 10.428 & 1 & 0.001 & & \\
\hline Fisher's exact test & & & & 0.002 & 0.001 \\
\hline Linear-by-linear association & 9.253 & 1 & 0.002 & & \\
\hline $\mathrm{N}$ of valid cases & 302 & & & & \\
\hline
\end{tabular}

a. 0 cells $(0.0 \%)$ have expected count less than 5 . The minimum expected count is 14.59 . b. Computed only for a $2 \times 2$ table.

Risk Estimate

\begin{tabular}{lccc}
\hline & Value & \multicolumn{2}{c}{ 95\% Confidence interval } \\
\cline { 3 - 4 } & & Lower & Upper \\
\hline $\begin{array}{l}\text { Odds ratio for utilization versus } \\
\text { non-utilization (utilization/non-utilization) }\end{array}$ & 0.265 & 0.107 & 0.655 \\
For cohort how long do you wait = quality & 0.701 & 0.593 & 0.829 \\
For cohort how long do you wait = not quality & 2.644 & 1.249 & 5.600 \\
N of valid cases & 302 & & \\
\hline
\end{tabular}

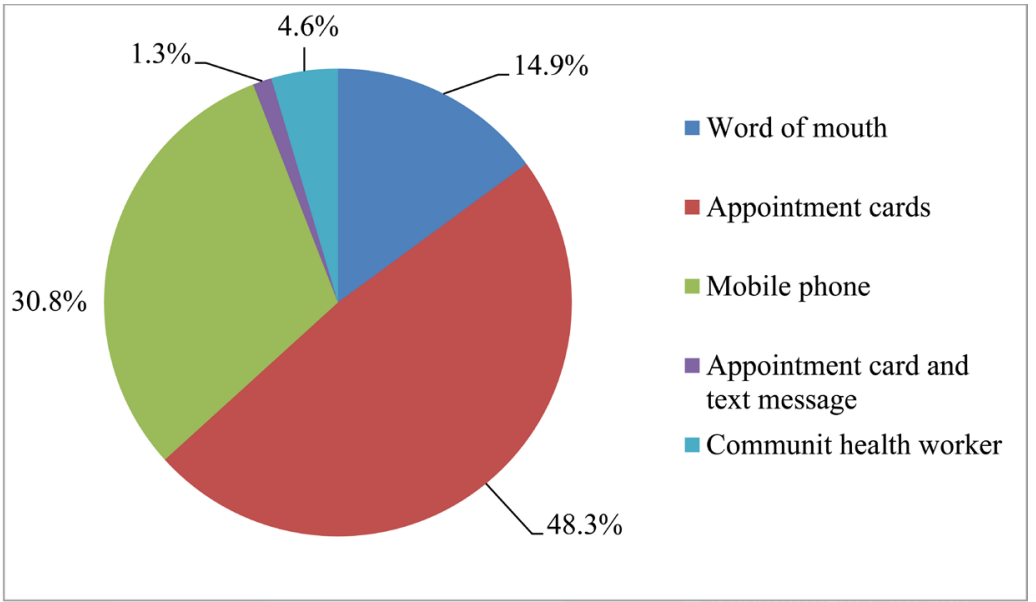

Figure 4. Methods of appointment reminder.

perception of health workers on integration; in Vietnam it was revealed that use of mobile phones and appointment cards are the most common methods of appointment reminder [18]. In another study, appointment card and text message is the most popular method of reminder [19].

Relative Involvement and Utilization of Integrated HIV and Primary Health Care Services

Most of the respondents $81.8 \%$ acknowledged that the facility had ever invited the family members to teach them on how to care for the patient at home, while 
$18.2 \%$ reported that no such invitation had ever been made (Figure 5). Involvement of relatives was cross-tabulation against utilization of HIV integrated primary health care services.

There was no association between involvement of relatives and utilization of integrated HIV and primary health care services $\left(\chi^{2}=0.159, \mathrm{df}=1, p=0.69\right.$; Table 8). The findings imply that involvement of family does not influence utilization. During the interview most respondent said that they were accompanied by the relative only the first day they started utilizing the facility. Some of them said that fear of discrimination and stigma prompt them not to involve some of their relatives. These findings agree with [7] that showed disclosure of the respondents' status to their families and involving them is non-significant to the level of utilization of the services.

Access of Information on Self-care and Utilization of Integrated HIV and Primary Health Care Services

Most respondents (89.1\%) accessed information of self care from health workers, $8.9 \%$ accessed information from family members while $2 \%$ accessed information from the media (Table 9). Primary source of information was supposed to be the health workers. Source of information was cross-tabulated against utilization.

Source of health care information significantly influenced utilization of integrated HIV and primary health care information $\left(\chi^{2}=10.698, \mathrm{df}=1, p=0.001\right.$;

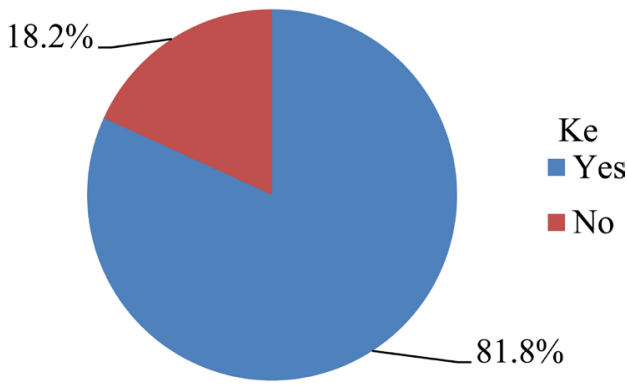

Figure 5. Involvement of relatives in patient care.

Table 8. Association between involvement of relatives and utilization of integrated HIV and primary health care services.

\begin{tabular}{cccccc}
\hline & Value & df & $\begin{array}{c}\text { Asymp. sig. } \\
(2-\text {-sided })\end{array}$ & $\begin{array}{c}\text { Exact sig. } \\
\text { (2-sided) }\end{array}$ & $\begin{array}{c}\text { Exact sig. } \\
\text { (1-sided) }\end{array}$ \\
\hline $\begin{array}{c}\text { Pearson chi-square } \\
\text { Continuity correction }{ }^{\mathrm{b}}\end{array}$ & $0.159^{\mathrm{a}}$ & 1 & 0.690 & & \\
$\quad 0.031$ & 1 & 0.860 & & \\
Likelihood ratio & 0.155 & 1 & 0.694 & & 0.417 \\
Fisher's exact test & & & & 0.661 & \\
Linear-by-linear association & 0.159 & 1 & 0.690 & & \\
N of valid cases & 302 & & & & \\
\hline
\end{tabular}

a. 0 cells $(0.0 \%)$ have expected count less than 5 . The minimum expected count is 7.10 . b. Computed only for a $2 \times 2$ table. 
Table 9). Majority of the respondents accessed information on self care from health care workers and the least $(2 \%)$ sourced the information from the media. The findings show that those who received information on self-care primarily from the health workers were 4.3 times likely to utilize integrated HIV and primary health care services (Table 9). The study findings are congruent with those of [5] that reported that poor staff communication prevented the patients from utilizing services offered in an integrated arrangement. The findings agree with [9] findings which showed that health workers provided general health education on all health topics including HIV prevention, care and treatment to both HIV and non-HIV patients (Table 10).

Kind of Treatment at Facility and Utilization of Integrated HIV and Primary Health Care Services

Most respondents (97.7\%) were treated with respect at the facility while $2.3 \%$

Table 9. Source of information on self-care.

\begin{tabular}{ccc}
\hline Information source & Frequency (n) & Percentage (\%) \\
\hline Health workers & 269 & 89.1 \\
Family members & 27 & 8.9 \\
Media & 6 & 2.0 \\
Total & 302 & 100.0 \\
\hline
\end{tabular}

Table 10. Association between source of self-care information and utilization of integrated HIV and primary health care services.

\begin{tabular}{cccccc}
\hline & Value & df & $\begin{array}{c}\text { Asymp. sig. } \\
(2 \text {-sided })\end{array}$ & $\begin{array}{c}\text { Exact sig. } \\
(2 \text {-sided })\end{array}$ & $\begin{array}{c}\text { Exact sig. } \\
(1-\text { sided })\end{array}$ \\
\hline $\begin{array}{c}\text { Pearson chi-square } \\
\text { Continuity correction }{ }^{\mathrm{b}}\end{array}$ & $13.736^{\mathrm{a}}$ & 1 & 0.000 & & \\
Likelihood ratio & 11.773 & 1 & 0.001 & & \\
Fisher's exact test & 10.698 & 1 & 0.001 & & 0.001 \\
Linear-by-linear association & 13.690 & 1 & 0.000 & & \\
N of valid cases & 302 & & & &
\end{tabular}

a. 1 cells $(25.0 \%)$ have expected count less than 5 . The minimum expected count is 4.26 . b. Computed only for a $2 \times 2$ table.

Risk Estimate

\begin{tabular}{llll}
\hline & Value & 95\% Confidence interval \\
\cline { 2 - 4 } & & Lower & Upper \\
\hline $\begin{array}{l}\text { Odds ratio for utilization versus non-utilization } \\
\text { (utilization/non-utilization) }\end{array}$ & 4.304 & 1.890 & 9.798 \\
For cohort how do you access info = quality & 1.276 & 1.045 & 1.559 \\
For cohort how do you access info = not quality & 0.297 & 0.156 & 0.563 \\
N of valid cases & 302 & & \\
\hline
\end{tabular}


were not treated with respect as shown in Figure 6. Respectful treatment was indicative of good quality service (Figure 6).

The kind of treatment was cross-tabulated against utilization of HIV integrated primary health care services. The treatment clients received at the facility influenced utilization of integrated HIV and primary health care services $\left(\chi^{2}=\right.$ 3.96) whereby those who were treated with respect were 5 times likely to utilize integrated HIV and primary health care services (Table 11). This findings are in agreement with [9] findings which indicated that various discriminatory behaviours and negative attitude towards HIV patients affect their utilization of the

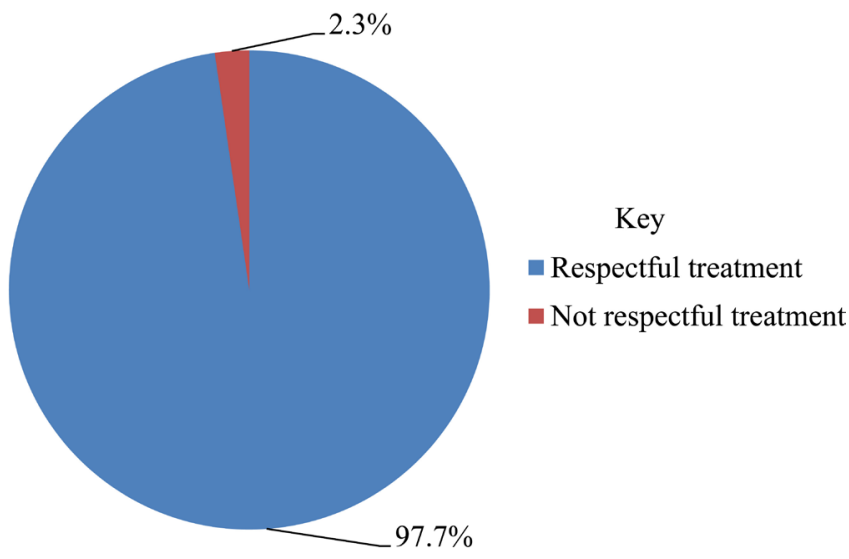

Figure 6. Kind of treatment at the health facility.

Table 11. Association between kind of treatment at facility and utilization of integrated HIV and primary health care services.

\begin{tabular}{|c|c|c|c|c|c|}
\hline & Value & df & $\begin{array}{l}\text { Asymp. sig. } \\
\text { (2-sided) }\end{array}$ & $\begin{array}{l}\text { Exact sig. } \\
\text { (2-sided) }\end{array}$ & $\begin{array}{l}\text { Exact sig. } \\
\text { (1-sided) }\end{array}$ \\
\hline Pearson chi-square & $5.713^{\mathrm{a}}$ & 1 & 0.017 & & \\
\hline Continuity correction ${ }^{\mathrm{b}}$ & 3.313 & 1 & 0.069 & & \\
\hline Likelihood ratio & 3.961 & 1 & 0.047 & & \\
\hline Fisher's exact test & & & & 0.048 & 0.048 \\
\hline Linear-by-linear association & 5.694 & 1 & 0.017 & & \\
\hline $\mathrm{N}$ of valid cases & 302 & & & & \\
\hline
\end{tabular}

a. 1 cells $(25.0 \%)$ have expected count less than 5 . The minimum expected count is 0.90 . b. Computed only for a $2 \times 2$ table.

Risk Estimate

\begin{tabular}{lccc}
\hline & Value & \multicolumn{2}{c}{$\mathbf{9 5 \% \text { Confidence interval }}$} \\
\cline { 4 - 5 } & & Lower & Upper \\
\hline $\begin{array}{l}\text { Odds ratio for utilization versus non-utilization } \\
\text { (utilization/non-utilization) }\end{array}$ & 5.396 & 1.160 & 25.094 \\
For cohort clients are usually treated with respect = yes & 1.067 & 0.973 & 1.169 \\
For cohort clients are usually treated with respect = no & 0.198 & 0.046 & 0.850 \\
N of valid cases & 302 & & \\
\hline
\end{tabular}


services. Some of the behaviours were denial of care, and testing or status disclosure without consent, verbal abuse, additional fee and overuse of gloves especially health care providers on HIV patients also affect their utilization level.

After bivariate analysis of the health service delivery factors that influenced utilization of integrated HIV and primary health care services, the study performed multiple logistic regression analysis on all those factors which had a $p$ value $<0.05$ from bivariate analysis. This was done using forward selection method. The results showed that action taken following side effects (Wald = $6.972, \mathrm{df}=1, p=0.008, \operatorname{EXP}(\mathrm{B})=3.4$ ), how long clients waited before service delivery (Wald $=7.361, \mathrm{df}=1, p=0.007, \operatorname{EXP}(\mathrm{B})=0.276$ ), and the primary source of self-care information (Wald $=5.095, \mathrm{df}=1, p=0.024, \mathrm{EXP}(\mathrm{B})=2.8$ ) contributed significantly to the overall change in the dependent variable (Table 12). Therefore, the null hypothesis that there were no service related characteristics influencing utilization of integrated HIV and primary health care services was rejected.

After forward selection, service delivery factors that influenced utilization of integrated HIV and primary health care services were action taken following side effects, duration of time one waited before service delivery and health care worker as the primary source of self care information.

\section{Conclusions}

Service delivery factors that influenced utilization were action taken when clients developed side effects; kind of treatment at the facility showing that those who were treated with respect were 5 times more likely to utilize integrated HIV and primary health care services. Other significant factors were the duration of time clients waited before service delivery and primary source of health care information. Most of the clients sought health services when they are sick or needed help for

Table 12. Regression analysis of service delivery factors influencing utilization of integrated HIV and primary health care services variables in the equation.

\begin{tabular}{|c|c|c|c|c|c|c|c|}
\hline & & B & S.E. & Wald & $\mathrm{df}$ & Sig. & $\operatorname{Exp}(B)$ \\
\hline \multirow{2}{*}{ Step $1^{\mathrm{a}}$} & What happened side effects & 1.510 & 0.422 & 12.784 & 1 & 0.000 & 4.527 \\
\hline & Constant & -3.667 & 0.546 & 45.133 & 1 & 0.000 & 0.026 \\
\hline \multirow{3}{*}{ Step $2^{b}$} & What happened side effects & 1.500 & 0.435 & 11.888 & 1 & 0.001 & 4.480 \\
\hline & How long wait & -1.319 & 0.469 & 7.927 & 1 & 0.005 & 0.267 \\
\hline & Constant & -1.982 & 0.772 & 6.601 & 1 & 0.010 & 0.138 \\
\hline \multirow{4}{*}{ Step $3^{c}$} & What happened side effects & 1.216 & 0.460 & 6.972 & 1 & 0.008 & 3.372 \\
\hline & $\begin{array}{l}\text { Health care worker as a } \\
\text { primary source of information }\end{array}$ & -1.287 & 0.474 & 7.361 & 1 & 0.007 & 0.276 \\
\hline & information 1 & 1.030 & 0.456 & 5.095 & 1 & 0.024 & 2.800 \\
\hline & Constant & -2.895 & 0.881 & 10.807 & 1 & 0.001 & 0.055 \\
\hline
\end{tabular}

a. Variable(s) entered on step 1: what happened side effects. b. Variable(s) entered on step 2: how long wait. c. Variable(s) entered on step 3: information 1. 
their health problems and the majority depend on health worker as main source of health care information. The findings show that those who received information on self-care primarily from the health worker were 4.3 times likely to utilize integrated HIV and primary health care services. Majority of the patients were satisfied with the duration of time they take before they are served; they reported that they take utmost 1 hour to be attended to which allow them to engage in other income-generating activities. Therefore, the null hypothesis that there were no service-related characteristics influencing the utilization of integrated HIV and primary health care services was rejected.

Action was taken when clients developed side effects significantly influenced utilization, whereby those who waited for 1 hour or less were unlikely to utilize the integrated services. Health worker as the primary source of self care information whereby those who received the information were on self care primarily from the health worker, were 4.3 times likely to utilize integrated health care services. The treatment the patients received at the clinic influenced utilization of integrated HIV and primary health care services, whereby those who were treated with respect were 5 times likely to utilize the facility.

\section{Acknowledgements}

I take this opportunity to appreciate everyone who has supported me and contributed to my writing this thesis. My Appreciation goes to my dedicated academic supervisors, Dr. Moses Muraya and to Dr. Micah Matiang'i for the untiring technical and moral support provided throughout the study process. I acknowledge Chuka University Management for giving me a chance to study and realize my full potential. Special thanks to Dr. Lucy Gitonga, the head of Nursing Department and entire Nursing Department fraternity for equipping me with knowledge and moral support throughout the study process. Exceptional gratitude goes to my family for their continued support both spiritual and financial support. Thanks to my colleagues at work and my classmates for their support throughout my master's program. My special appreciation goes to administrative officers in Embu Level Five, Comprehensive Care Clinic in charge and peer support workers for their unwavering support during collection of my research data. Thank you all for your support.

\section{Conflicts of Interest}

The authors declare no conflicts of interest regarding the publication of this paper.

\section{References}

[1] UNAIDS (2018) The Global HIV/AIDS Epidemic. https://www.hiv.gov/hiv-basics/overview/data-and-trends/global-statistics

[2] Kimberly, G. (2015) HIV Service Delivery Models towards Zero Aids Related Deaths. BMC Health Service Research, 15, 12-15.

[3] Johnson, K. (2013) Integration of HIV and Family Planning Health Services in 
Sub-Saharan Africa. DHS Analytical Studies No. 30, Calverton.

[4] Mutemwa, R. (2016) Perception and Experiences of Integrated Service Delivery among Women Living with HIV Attending Reproductive Health Services in Kenya: A Mixed Methods Study. AIDS and Behaviour, 20, 2130-2140. https://doi.org/10.1007/s10461-016-1373-2

[5] Bergh, A. (2015) Clinician Perceptions and Patient Experiences of ART Treatment and Primary Health Care Integration in ART Clinics. AOSIS Open Journal, 38, 1489. https://doi.org/10.4102/curationis.v38i1.1489

[6] Sima, B.T., Belachew, T. and Abebe, F. (2017) Knowledge, Attitude and Perceived Stigma towards Tuberculosis among Pastoralists. PLoS ONE, 12, e0181032.

https://doi.org/10.1371/journal.pone.0181032

[7] Pathmanathan, I., et al. (2017) High Uptake of Antiretroviral Therapy among HIV-Positive TB Patients Receiving Co-Located Services in Swaziland. PLoS ONE, 13, e0196831. https://doi.org/10.1371/journal.pone.0196831

[8] Buh, W., Peter, N. and Atashili, J. (2016) Clients Satisfaction with HIV Treatment Services in Bamenda, Cameroon. BMC Health Services Research, 16, 280.

https://doi.org/10.1186/s12913-016-1512-5

[9] Kikuvi, J. (2014) Are Integrated HIV Services Less Stigmatizing than Stand Alone Models of Care? A Comparative Case Study from Swaziland. International Aids Society, Geneva.

[10] Kioko, J. (2015) Are Integrated HIV Services Less Stigmatizing than Stand Alone Models of Care? A Comparative Case Study from Swaziland. Journal of International Aids Society, 16, 9-12.

[11] National AIDS Control Council, NACC (2016) Kenya HIV County Profiles. Ministry of Health, Nairobi.

[12] Odeny, T.K.J. (2013) Intergration of HIV Core with Primary Health Care Services: Effects of Patient Satisfaction and Stigma in Rural Kenya. AIDS Research and Treatment, 20, 4-8. https://doi.org/10.1155/2013/485715

[13] Tran, B.X. and Nguyen, N.P. (2012) Patient Satisfaction with HIV/AIDS Care and Treatment in the Decentralization of Services Delivery in Vietnam. PLoS ONE, 7, e46680. https://doi.org/10.1371/journal.pone.0046680

[14] Risenga, P. and Ndou, T. (2016) HIV Positive Patients' Perceptions of Care Received at a Selected Antiretroviral Therapy Clinic in Vhembe District. Africa Journal of Primary Health Care and Family Medicine, 8, a926. https://doi.org/10.4102/phcfm.v8i2.926

[15] Chuah, F.H.-L. (2017) Interventions and Approaches to Integrating HIV and Mental Health Services: Systemic Review. Health Policy and Planning, 32, $27-47$. https://doi.org/10.1093/heapol/czw169

[16] Mathibe, M. (2015) Clinician Perception and Patient Experiences of Antiretroviral Treatment Integration in Primary Health Care. Africa Journal of Primary Health Care, 8, 21-26.

[17] Obinna Onwujekwe, I.C. (2015) Investigating Client Perception and Attitude to Decentralization of HIV/AIDS Treatment Services to Primary Health Centres. Public Participation in Health Care and Health Policy, 19, 1111-11120. https://doi.org/10.1111/hex.12403

[18] Crowley, T. (2014) Integrating HIV Care and Treatment into Primary Health Care: Are Clinics Equipped? National Institute of Health, Bethesda. https://doi.org/10.4102/phcfm.v6i1.616 
[19] Bintabara, D., Nakamura, K. and Seino, K. (2017) Determinants of Facility Readiness for Integration of Family Planning with HIV Testing and Counseling Services: Evidence from the Tanzania Service Provision Assessment Survey, 2014-2015. BMC Health Service Research, 17, 844. https://doi.org/10.1186/s12913-017-2809-8 